\title{
The impact of using Mobile Social Network Applications on Students' Social-Life
}

\author{
Ahmed Yousif Abdelraheem \\ Assoc. Prof., Sultan Qaboos University, College of Education, Oman, \\ ahmedyar@squ.edu.om
}

\author{
Abdelrahman Mohammed Ahmed \\ Dr., Sultan Qaboos University, College of Education, Oman, abdoelhaj@squ.edu.om
}

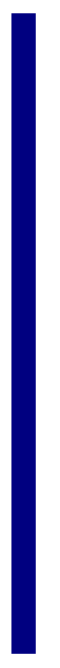

The aim of the study was to investigate the impact of using Mobile Social Network Applications (MSNAs) on students' social life (social relations, family relations and social awareness). The study was designed as a survey study using a five-point Likert-type scale to collect data from the students. A sample of 211 students' response was analyzed. The results indicated that: the overall impact of MSNAs was found to be at moderate degree $(\mathrm{M}=3.23)$. Also, social relation, family relation and awareness of current issues were found to be of the same degree $($ Means $=3.41,3.23,3.61)$ respectively. Compression of the means of the three dimensions with the theoretical means revealed significant differences in favour of each dimension. T-tests compressions for the gender and for education level revealed no significant differences in both variables whereas significant differences were found for the time spend variable. ANOVA for purposes of using (MSNAs) showed significant difference in favour of educational purposes, while ANOVA for type of applications used revealed no significant differences. The study concluded that the use of (MSNAs) at a moderate degree on students' social life and recommended the use of a large sample and scale of more variables of social life.

Keywords: mobile, social networks, social media, social relation, family relation, and social awareness

\section{INTRODUCTION}

With the increase use of new technology for instruction and communicating with others and the popularity of the Internet, Social Network Sites (SNS) have become an activity that is done primarily on the Internet. New technologies have the potential to support all generations. In many cases technology must be retrofitted to meet the diverse needs of all users (Sanche z-Gordon \& Luján-Mora, 2016). The same is true with mobile devices and apps. Today, mobile phones and the social network applications have become

Citation: Abdelraheem, A. Y., \& Ahmed, A. M. (2018). The impact of using Mobile Social Network Applications on Students' Social-Life. International Journal of Instruction, 11(2), 1-14. https://doi.org/10.12973/iji.2018.1121a 
popular to everybody since they are very handy; with a mobile phone in our hand we can solve many issues and keep individuals connected to society, especially college students (Chatterjee, 2014; Jesse, 2015). In addition, social network applications have become one of the most important communication means in recent times. However, social networking exists so as to provide communication among people to stay connected on a new level that does not depend on space or time, but is readily accessible at anytime, anywhere (Chatterjee, 2014). The favorite in the realm of internet sites are Facebook, Twitter, YouTube, MySpace, Whats app and others. These websites and social forums are way of communication directly with other people socially and in media. They are playing a large and influential role decision-making in the occasions from the global world economically, politically, socially and educationally (Al-Rahmi \& Othman, 2013). Many research studies have provided evidence that social network applications provide people many affordances when using in educational settings (Ferdig, Pytash, Kosko, Gandolfi, \& Mathews, 2016, AbdelRaheem, 2015; Alqahtani \& Mohammad, 2015). Scholars have investigated the ease of personalized and collaborative learning with mobile social network applications, as well as an increase in students' motivation (Alvarez, Alarcon, \& Nussbaum, 2011; Chiang, Yang \& Hwang, 2014). On the other hand, some studies reported that student's use of mobile social network applications disrupts teaching and reduces student's attention in class, resulting in negative educational outcomes. However, a review of literature revealed that there were scant studies of the use of the impact of the MSNAs on students' social life (Eteokleous et al., 2012; Rajeev \& Jobilal, 2015).

The majority of the college of education students at Sultan Qaboos University has used MSNAs and they are actively using them especially when socializing with their peers. The students are spending a lot of time in these online communities and on their mobile phones that are internet enabled accessing the SNSs while at home. They spend long hours chatting with friends, classmates, going through friends' profiles and improving their own profiles. Given that significant role that social network applications are playing in people lives, parents and instructors are understandably concerned whether these social network applications and communities have an impact on their social life in terms of social relations, family relations and social awareness. This concern has prompted this research and we chose to do it because we think attention must be placed on college students and the impact of MSNAs on their social life. Therefore, the aim of this study is to investigate the impact of using MSNAs on students' social life at the college of Education at Sultan Qaboos University.

\section{LITERATURE REVIEW}

Social networks sites have changed today the way of human communications. From simple beginnings as a platform for sharing photos, discussing common interests, and supplementing traditional social interactions, they have become the source of change in different fields (Abdelraheem, 2013). College students now use the Internet for the majority their daily activities and information gathering, as opposed to older generations of students who used resources like the television or newspaper. A survey study conducted by Kist (2008) showed that approximately half of all teens in the United 
States who have Internet access are members of SNS, and they used these networking sites to make plans and socialize with friends (Kist, 2008). According to Tariq, Mehboob, Khan \& Ullah (2012) survey study, 90\% of college students use social networks. Technology has shown a rapid development by introducing small communication devices and we can use these small communication devices for accessing social networks at any time anywhere, as these gadgets include pocket computers, laptops, iPads and even simple mobile phones (which support internet) etc. (Tariq et al., 2012). Some studies suggest that SNS may connect students to the broader community. For example, Ahn (2010) finds that students who are members of Facebook and MySpace report substantially larger levels of social capital than their peers who are not members.

The University of New Hampshire believes that current college students grew up in the technology era and social networking is now just a part of a student's daily routine. Their research show that ' $63 \%$ of heavy users received high grades, compared to $65 \%$ of light users' (U of NH, 2009). The report showed that a majority of students use social networking for social connections and entertainment, but are also using it for education and professional reasons. Paul, Baker \& Cochran (2012), in their research on effect of online social networking on student academic performance found that there is statistically negative relationship between time spent by students on social networks and their academic performance. Banquil \& Chua (2009) concluded that social networking sites do affect one's academic performance adversely. It directly causes the gradual drop of grades of students and directly affects their academic performance if they invest their time in social networking sites instead in their studies (Banquil \& Chua, 2009).

Many research showed that the use of SNSs and mobile applications impact students' social life, academic performance and relationship (Stollak, Amy, Andie \& Stephanie, 2011; Wang, Chen \& Liang, 2011; Mehmood \& Taswir, 2013; Waigumo, 2013; Abdelraheem, 2013; Rajeev \& Jobilal, 2015; Jesse, 2015). According to a research study conducted by Siibak (2009) on visual impression management and social networking sites, found that approximately $60 \%$ of adolescents spend more time selecting which pictures to post on their profile than actually communicating with others. This shows that these SNSs are not just for keeping in touch with classmates and meeting new people, they are used to build adolescent identities (Siibak, 2009). Similarly, a survey study conducted by Kist (2008) showed that approximately half of all teens who have Internet access are also members of social networking sites, and they use the Internet to make plans and socialize with friends (Kist, 2008). Another study conducted by Stollak, Amy, Andie \& Stephanie (2011) explored the impact of social networking usage on grades among college students. They found that students who have smart phones were more likely to both access social media tools and spend time engaging with others. Their study showed that juniors and seniors students were more likely to use Twitter and LinkedIn, and read blogs, than their younger colleagues. However, other than Facebook, there was no significant difference in the amount of time spent accessing these sites. 
Wang, Chen \& Liang (2011) presented a survey study on how social media affects college students. The study also examined the student perception on how social media affects college students. The results of the survey indicated that $45 \%$ of the sample admitted that they spent 6-8 hours per day checking social media sites, while $23 \%$ spent more than 8 hours; $20 \%$ spent $2-4$ hours and only $12 \%$ spent less than 2 hours on this task. Their results also showed that while most college students use social media and spend many hours checking social media sites, there was a negative aspect to college students' use of social media. Similarly, Mehmood \& Taswir (2013) investigated the pedagogical impacts of SNSs on undergraduate students at the College of Applied Sciences (CAS), Nizwa, Oman. Their study explores classroom and social software as paradigms that build young knowledgeable societies. It studies variables that examine the effectiveness of these social tools in knowledge sharing and general awareness of student communities. Their results showed that $80 \%$ of the students used SNSs on phone. The results also found that $44 \%$ of the students had more friends online than in real life. The study also found that $60 \%$ of the students spent two hours and more per day. Moreover, the study found that the number of social networks used by the students also varied. It showed that $42 \%$ of the students used two and $48 \%$ of them used more than three social networks. Nearly all respondents were members of a community or a group on social networks. The kind of communities they joined was for educational, entertainment, information and for any other uses. The maximum groups and communities joined by students were for information and awareness purposes. Waigumo (2013) conducted a descriptive survey study to examine if SNSs have any impact on interpersonal relationships among teenagers. His research also aimed to determine the impact of SNSs usage on teenagers' offline and online interpersonal relationships as well as to look at the term social capital and its relationships with social networking sites. The study found out that SNSs have an impact on interpersonal relationships among teenagers; they mostly improved their relationships among one another thus bridging and bonding social capital. The results also found that, although the SNSs have helped to improve the relationships among close teenagers as friends, they have also made the teenagers not to be able to build interpersonal relationships among other friends who are not close to them. They have inhibited the teenagers from being able to express themselves face to face especially to the members of the opposite sex. The results also showed that, the teenagers are spending a lot of time on their mobile phones accessing the SNSs at the expense of going out to find friends to interact with face to face. Abdelraheem (2013) investigated the students' use of SNSs and its relation to gender, type of use, GPA, type of mobile phones and types of sites. The results show that students use SNSs for social matters more than for academic purposes, there is no difference in using SNSs between female students and male students. The results also found that there is no significant difference in students' use of SNSs due to student's GPA. More than fifty percent of students' sample spent two hours or more than two hours per day.

Jesse (2015) explored the relationships between smartphone usage and the effects smartphones have on student's social lives, education lives, and physical activity. Furthermore, they explored student preferences on their most and the least useful 
smartphone apps. Their results found that: prefer Android preferred Operating System, approximately 25 apps installed, most useful apps are Utility Apps; least useful are Travel Apps, most used are Social Media, open Primary app 6 times a day, and Facebook is the primary social media app. The result showed that students are still using their cellphones for communication and to stay in touch with each other; students have discovered a new way of staying connected with their friends. Smartphones and their apps are two technologies that impact a student's education and psychological wellbeing. Rajeev \& Jobilal (2015) studied the various impacts of mobile social networking sites among the youth in social relationships. Their study concluded that the mobile phone has influenced on young people's peer groups enabling a truly networked society. It has also impacted the evolving relationships within the family; especially by the increased negotiating power the mobile phone gives to young people in regard to curfews and safety issues. Schools and educational settings report that student's mobile phone use disrupts teaching and reduces student's attention in class, resulting in negative educational outcomes. Recent study conducted by Siddiqui \& Singh (2016) which aimed to explore and cover all aspects of social media with its positive and negative effect. They concluded that social media has increased the quality and rate of collaboration for students. They pointed that one of the negative effect of social media is that it makes people addicted. People spend lots of time in social networking sites which can divert the concentration and focus from the particular task. Social lies like family ones also weaken as people spend more time connecting to new people (Siddiqui \& Singh, 2016). Accordingly, the aim of this study is to investigate the impact of using MSNAs on students' social life at the college of Education at Sultan Qaboos University. The study investigates the impact of using MSNAs on students according to the academic level, gender, time spend on social network applications, type of social network applications and the purpose of utilization factors. With this concern in mind this study addresses the following questions:

1. What is the impact of MSNAs on some aspects of students' social life (social relations, family relations and social awareness)?

2. Are there any significant differences in means of overall impact, social relation dimension, family relation dimension, and awareness about social issues dimension and the theoretical mean $(\mathrm{M}=3)$ for each of them?

3. Does the impact of MSNAs on students' social life vary according to:

a. gender

b. academic level

c. time spend on social media applications

d. type of social media applications

e. purpose of utilization

\section{Importance of the study}

The findings of this study can help administrators, instructors, parents and decision makers to recognize the extent to which university students use MSNAs and how that will impact their social life. Therefore, the positive result of this study may enable 
decision makers to make judgments on the current situation of the impact of the use of MSNAs on the students' social life.

\section{METHOD}

The present study was primarily carried out with a quantitative approach using a survey methodology. It was carried out during the 2017 spring semester at Sultan Qaboos University in Oman. The purpose of collecting data was to perform a research on how MSNAs affect the social life of students of the College of Education. The data for this study was collected by way of a survey questionnaire administered to 211 undergraduate and postgraduate students during the 2016/2017 academic year (Appendix A). The total number of questionnaires administered were 250 , however the usable questionnaires were $(\mathrm{N}=211)$. The questionnaire was collected from the sample through direct contact and online using Google forms sending them the links through their emails. The researchers reminded the participants to respond to the questionnaire from time to time until they got 211 respondents. After that, the data were analyzed by the suitable statistics (Descriptive statistics, $\mathrm{t}$ test, and ANOVA) to obtain the answers to the research questions.

\section{Sample}

The sample of this study consisted of 60 males and 151 females. Forty-four respondents were postgraduate students and 161 respondents were undergraduate students. Students were instructed in the survey to offer information about their educational level, social network applications, purpose of the use, time, and impact of using MSNAs on their social life.

\section{Instrument}

In order to develop the instrument, the researchers surveyed the literature to obtain some initial information regarding the use of social network sites by students. The instrument consists of two sections. The first section collects demographic data, whilst the second section consists of 39 items, 15 items for use of MSNAs on social relations, 14 items for use of MSNAs on family relations and 10 items for use of MSNAs on social awareness. The survey was expected to take ten to fifteen minutes to be completed, and the instrument was given to a panel of faculty members for face validation. They reviewed the instrument and gave some suggestions, which the researchers used to revise the instrument accordingly. The reliability coefficient of the instruments was measured by alpha Cronbach and was found to be 0.86 for social relations, 0.85 for family relations, and 0.87 for social awareness respectively. After that, the instrument was ready for distribution to the study sample to obtain the necessary data.

\section{FINDINGS}

To answer the first question of the study which related to the impact of MSNAs on some aspects of students' social life (social relations, family relations and social awareness), descriptive statistics for 39 items of the instrument with a five-point Likert-type scale were conducted. The results are shown in table (1) below. 
Table 1

Means and standard deviations for the students' responses to the scale.

\begin{tabular}{|c|c|c|c|c|c|c|c|}
\hline Items & $\mathrm{N}$ & Mean & Std. Deviation & Items & $\mathrm{N}$ & Mean & Std. Deviation \\
\hline Item 1 & 211 & 3.9100 & 1.24075 & Item 21 & 210 & 2.4095 & 1.23114 \\
\hline Item 2 & 211 & 4.5592 & .79285 & Item 22 & 208 & 3.7885 & 1.21324 \\
\hline Item 3 & 204 & 3.5049 & 1.20956 & Item 23 & 203 & 2.5517 & 1.30157 \\
\hline Item 4 & 210 & 3.3238 & 1.34481 & Item 24 & 208 & 2.3558 & 1.20721 \\
\hline Item 5 & 208 & 3.2981 & 1.24629 & Item 25 & 209 & 2.5550 & 1.10857 \\
\hline Item 6 & 208 & 2.2356 & 1.21873 & Item 26 & 210 & 2.4095 & 1.26185 \\
\hline Item 7 & 207 & 3.3816 & 1.21649 & Item 27 & 209 & 3.7464 & 1.23949 \\
\hline Item 8 & 204 & 2.6618 & 1.26659 & Item 28 & 208 & 3.4423 & 1.05708 \\
\hline Item 9 & 207 & 3.4010 & 1.14000 & Item 29 & 210 & 3.6619 & 1.08710 \\
\hline Item 10 & 210 & 3.1714 & 1.16944 & Item 30 & 209 & 3.6651 & 1.12779 \\
\hline Item 11 & 207 & 3.1836 & 1.33479 & Item 31 & 208 & 3.3942 & 1.18296 \\
\hline Item 12 & 207 & 3.6280 & 1.00571 & Item 32 & 209 & 3.5933 & 1.13178 \\
\hline Item 13 & 209 & 3.4498 & 1.04634 & Item 33 & 208 & 3.5000 & 1.27404 \\
\hline Item 14 & 210 & 3.2714 & 1.07501 & Item 34 & 209 & 3.7368 & 1.08868 \\
\hline Item 15 & 210 & 2.9333 & 1.21605 & Item 35 & 204 & 3.6961 & 1.19761 \\
\hline Item 16 & 210 & 2.3905 & 1.19405 & Item 36 & 207 & 4.3285 & .98450 \\
\hline Item 17 & 209 & 2.9043 & 1.28991 & Item 37 & 209 & 3.1962 & 1.21084 \\
\hline Item 18 & 209 & 2.9952 & 1.23451 & Item 38 & 207 & 3.2126 & 1.19596 \\
\hline Item 19 & 209 & 2.8612 & 1.21088 & Item 39 & 208 & 3.2692 & 1.18142 \\
\hline Item 20 & 205 & 2.4780 & 1.27408 & SUM & 211 & 3.2322 & .48737. \\
\hline
\end{tabular}

It is clear that from the above table (Table 1) item 2 "to allow me to communicate easily" has the highest mean score (mean=4.5592) and this mean fall within the range of (4.21-5), which indicates that this item has high impact on students' social relation. This means that MSNAs have positive influences in people social relation, including the ability to communicate with more people across greater distances and with increased speed. Table 1 also showed that item 36 "to raise social awareness on the current events" has high mean score (mean $=4.3285$ ) and this mean fall within the range of (4.21-5), which indicates that this item has high impact on the awareness of social issues. This is could be explained by the fact that many people use social network applications to express their personal opinions about current events and news' issues to their friends. Increasing awareness about social issues through current events will affect the students' social life in the long range. In addition, social network sites can be used to share materials (video files, audio files, pictures, web sites etc.) effectively, follow up current events, news, people or groups, and get involved in discussion environments to support the skills of learning for cooperation, research, discussion, critical thinking, problem solving and so on (Tiryakioglu \& Erzurum, 2011). The table also showed that item 1 "to allow me to meet new people" has the high mean score $($ mean= 3.9100) and this mean fall within the range of (3.41-4.2), which indicates that this item has high impact on students' social relation. Meeting and connecting with new people might lead to strengthen the social ties among people. This could be justified by the fact that social network applications have become an extremely important tool for sharing communication and making new friendships. SNS has provided more channels for people to meet new people. It also provides support for users to link up with current and 
past friends, and friends of friends, and to make new friends they have never met (Zhang, Gao, Khoo \& Wu (2013).

Table 1 also showed that item 6 "I prefer chatting through online media than communicating orally with others" received lowest rating mean score (mean=2.2356) and this mean fall within the range of $(1.81-2.6)$, which indicates that this item has little impact on students' social relation. This item indicated that students might find themselves isolated fiscally but connected virtually and in both cases that might lead to affect their social relation positively or negatively. Item 16 (I feel that my activities and contributions to family events have been reduced since I used MSNAs) also receive lowest rating mean score (mean $=2.3905)$ and this mean fall within the range of $(1.81-$ 2.6), which indicates that this item has lower impact on students' family relation. This item showed the positive impact of using MSNAs on students' family relation. MSNAs have become important communication tools, particularly for family, which help people to communicate between them and inform each other about the current news and events. This result was supported by Rajeev \& Jobilal (2015) who conclude that mobile phone has influenced on young people and impacted the evolving relationships within their family. The overall impact of using MSNAs on some aspects on students' social life was found to be at a moderate level (mean= 3.23). It is clear from the above discussion in this section that social relations are strengthened and expanded by using MSNAs. These tools could help to gain an understanding of other cultures, meet people all over the world, maintain and strengthen familial relationships and to communicate effectively with others. Also using MSNAs to exchange information through current events about social issues might affect students' social life in general.

To answer the second question which states "Are there any significant differences in means of overall impact, social relation dimension, family relation dimension, and awareness about social issues dimension and the theoretical mean $(M=3)$ for each of them?" One sample t-test was calculated to test for significant. The results were shown in table 2 .

Table 2

One sample t-test for scale dimension 1,2,3 and total (comparing means with the theoretical mean)

\begin{tabular}{llllllll}
\hline Dimension & $\mathrm{N}$ & Mean & $\mathrm{SD}$ & $\mathrm{df}$ & $\mathrm{t}$ & $\mathrm{Sig}$ & Size effect \\
\hline D1 (social relation dimension) & 211 & 3.41 & .59251 & 210 & 8.709 & .000 & 0.7 \\
D2 (family relation dimension) & 211 & 3.23 & .48737 & 210 & 6.920 & .000 & 0.5 \\
D3(social issues dimension) & 211 & 3.61 & .78793 & 210 & 10.432 & .000 & 0.7 \\
Total & 211 & 3.23 & .48737 & 210 & 6.920 & .000 & 0.5 \\
\hline
\end{tabular}

It is clear from the above table that there is a significant difference at $\alpha 0.05$ in the total mean as compared to the theoretical mean for the impacts of the use of MSNAs on some aspects of students' social life (mean $=3.23 ; \mathrm{p}<0.05$ ). The table also showed that the total impact of using MSNAs has moderate mean score and this mean fall within the range of (2.61-3.4), which indicates that the impacts of the use of MSNAs on students' social life has a moderate degree of influence. 
In terms of the social relation dimension, table 2 indicates that there is a significant difference at $\alpha 0.05$ in the mean as compared to the theoretical mean for the use of MSNAs in social relation (mean $=3.41 ; \mathrm{p}<0.05$ ). The table also showed that the use of MSNAs in social relation has high mean score and this mean fall within the range of (3.4-4.2), and the use of MSNAs in social relation has high degree of influence. This result is justified because these mobile applications when invented were mainly for social collaboration and communication and assist people in developing better relationships. This result is supported by many research findings e.g., (Stollak, Amy, Andie \& Stephanie, 2011; Wang, Chen \& Liang, 2011; Mehmood \& Taswir, 2013; Waigumo, 2013; Abdelraheem, 2013; Rajeev \& Jobilal, 2015 \& Jesse, 2015).

Regarding family relations dimension, table 2 indicates that there is a significant difference at $\alpha 0.05$ in the mean as compared to the theoretical mean for the use of MSNAs in family relations (mean $=3.23 ; \mathrm{p}<0.05$ ). The table also showed that the use of MSNAs in family relations has moderate mean score and this mean fall within the range of (2.61-3.4), which indicates that the use of MSNAs in family relation has moderate degree of influence.

In terms of the social awareness dimension, table 2 indicates that there is a significant difference at $\alpha 0.05$ in the mean as compared to the theoretical mean for the use of MSNAs in social awareness (mean $=3.61 ; \mathrm{p}<0.05$ ). The table also showed that the use of MSNAs in social awareness has high mean score and this mean fall within the range of (3.4-4.2), and the use of MSNAs in social awareness has high degree of influence. This result could be viewed in term of immediate reactions to the items in this dimension. The respondents react to the environmental condition, food and nutrition, current issues etc.; because those issues could affect their life in both short term and long term. Issues like medical treatment will be taken seriously by individual because they have great impact in their social life.

To answer question three (a, b \& c) which states "Does the impact of MSNAs on some aspects of students' social life vary according to gender, academic level and time spend variables?" Independent sample t-test was used for each variable. The results were shown in table 3, 4 and 5.

Table 3

Independent sample t-test scores for differences in means of the MSNAs usage and gender

\begin{tabular}{llllllll}
\hline & groups & $\mathrm{n}$ & Mean & $\mathrm{sd}$ & $\mathrm{df}$ & $\mathrm{t}$ & Sig. (2-tailed) \\
\hline \multirow{2}{*}{ Gender } & Male & 60 & 3.2375 & 0.4783 & 208 & .034 & .97 \\
& Female & 150 & 3.2350 & 0.4934 & & & \\
\hline
\end{tabular}

As seen in Table 3, an independent-sample t-test was conducted to compare the means of students' use of MSNAs in their social life with respect to the gender variable. It is clear from Table 3 that there is no significant difference due to this variable for the 39 items of the use of MSNAs in social life $(\mathrm{t}=.034, \mathrm{p}>0.05)$. These results in agreement with Agbatogun (2013) and Abdelraheem (2013) results who reported that gender did not make any significant contribution to the use of social networks sites. However, there 
were some research findings contradicted this result, Ruleman (2012) suggested that females are more likely to use communication social tools (e.g., Facebook) than males.

Table 4

Independent sample t-test scores for differences in means of the MSNAs usage and academic level

\begin{tabular}{llllllll}
\hline & groups & $\mathrm{n}$ & Mean & $\mathrm{sd}$ & $\mathrm{df}$ & $\mathrm{t}$ & Sig. (2-tailed) \\
\hline Academic level & Undergraduate & 161 & 3.1748 & 0.4731 & 203 & -3.35 & .001 \\
& Postgraduate & 44 & 3.4446 & 0.4699 & & & \\
\hline
\end{tabular}

It is clear from Table 4 that there was a significant difference in the scores for undergraduate and postgraduate students for MSNAs usage in social life ( $\mathrm{t}=-3.35$, $\mathrm{p}<0.05)$ in favour of postgraduate students. Postgraduate students reported a significantly higher mean value (3.4446) than undergraduate (3.1748) for MSNAs usage. This result may be explained by the fact that postgraduate students are exposed to use MSNAs as learning and communication tools in social commutation more than undergraduate students. They form useful groups in order to benefit from them and for just wasting time.

Table 5

Independent sample t-test scores for differences in means of the MSNAs usage and time spend on social media applications

\begin{tabular}{llllllll}
\hline Time spend & groups & $\mathrm{n}$ & Mean & $\mathrm{sd}$ & $\mathrm{df}$ & $\mathrm{t}$ & Sig. (2-tailed) \\
& three hours and less & 144 & 3.1806 & 0.4464 & 202 & -2.72 & .007 \\
& more than three hours & 60 & 3.3836 & 0.5658 & & & \\
\hline
\end{tabular}

As seen in Table 3, an independent-sample t-test was conducted to compare the means of students' use of MSNAs in their social life with respect to the time spend variable. Table 3 indicates that there was a significant difference in the scores for time spend on MSNAs usage in social life $(\mathrm{t}=-2.72, \mathrm{p}<0.05)$ in favour of more than three hours. As the time for the use increases there will be chance for the impact to increase. in other word there is a direct relating between the time spend on using SNMAs and its impact of social relation. The results of this study in agreement with those of (Abdelraheem, 2013; Mehmood \& Taswir, 2013) who indicated that more than $60 \%$ of students' sample spent two hours or more than two hours per day using social network sites. Moreover, this result, was supported by (Stollak et al., 2011) in their study in which they found that senior students were more likely to use Twitter and LinkedIn, and read blogs, than their younger colleagues.

To answer question three (d) which states "Does the impact of MSNAs on some aspects of students' social life vary according to the purpose of utilization variables?" ANOVA test was used. The results were shown in table 6 and 7. 
Table 6

Means and standard deviations of students' use of MSNAs and purpose of utilization

\begin{tabular}{llll}
\hline & $\mathrm{N}$ & Mean & Std. Deviation \\
\hline Social & 39 & 3.0839 & .43960 \\
Educational & 12 & 3.3027 & .61309 \\
Both social \& educational & 150 & 3.2880 & .46327 \\
Total & 201 & 3.2493 & .47320 \\
\hline
\end{tabular}

It is clear that from the above table (Table 6) that "the educational" use of MSNAs has the highest mean score $($ mean $=3.3027)$ as compare to social and both social \& educational purposes.

Table 7

ANOVA for mean difference in usage of MSNAs with respect to purpose of utilization

\begin{tabular}{llllll}
\hline & Sum of Squares & df & Mean Square & F & P \\
\hline Between Groups & 1.327 & 2 & .663 & 3.023 & .051 \\
Within Groups & 43.456 & 198 & .219 & & \\
Total & 44.783 & 200 & & & \\
\hline
\end{tabular}

It is clear from Table 7 that there were significant differences among the three groups of purpose of utilization (social, educational, and both social \& educational) on MSNAs usage in social life. To check for direction of the significant, Scheffe paired wise comparison was used. It was found that using MSNAs for educational purpose was higher than using them for social and both social \& educational purposes. And there were no significant differences between social and both social \& educational. This result could be explained by taking into consideration the point that two third of the respondents' sample were female, and they prefer to use MSNAs for educational purpose rather than social. Moreover, the use of social media by female is very limited, because Omani society is very conservative society in which female her not allowed to socialize in a wide range. This result is contradicted by which the University of New Hampshire report. The report found that a majority of students use social networking sites for both social and educational purpose (U of NH, 2009). Also this result contradicts AbdelRaheem's (2013) finding in which he stated that students' use SNSs for social purposes more than for educational purposes.

To answer question three (e) which states "Does the impact of MSNAs on some aspects of students' social life vary according to the type of applications?" ANOVA test was used. The results were shown in table 8 and 9 .

Table 8

Means and standard deviations of students' use of the type of applications

\begin{tabular}{llll}
\hline & $\mathrm{N}$ & Mean & Std. Deviation \\
\hline One applications & 38 & 3.1188 & .50227 \\
Two applications & 41 & 3.2117 & .57171 \\
3 and more applications & 128 & 3.2783 & .45630 \\
Total & 207 & 3.2358 & .49082 \\
\hline
\end{tabular}


It is clear that from the table 8 that " 3 and more type of applications" has the highest mean score (mean $=3.2783$ ) as compare to one and two applications.

To check for significant ANOVA test was used in table 9.

Table 9

ANOVA for mean difference in usage of MSNAs with respect to the type of applications

\begin{tabular}{llllll}
\hline & Sum of Squares & df & Mean Square & F & p \\
\hline Between Groups & .775 & 2 & .388 & 1.618 & .201 \\
Within Groups & 48.850 & 204 & .239 & & \\
Total & 49.625 & 206 & & & \\
\hline
\end{tabular}

As indicated in Table 9 there is no significant difference in the means of the type of applications which means that the use of different type of MSNAs has no effect on the social life of the student. This result could be justified by the fact that, most people used different SNS (e.g., Facebook, Twitter, WhatsApp ...) to communicate and share almost everything in their social life, such as information, ideas, pictures, events, news, with their friends and families. This result is supported by Mehmood \& Taswir (2013) findings, which showed that $90 \%$ of the students used more than two social networks.

\section{CONCLUSION AND RECOMMENDATION}

Now a day's MSNAs have been the important part of one's life from shopping to electronic mails and education tool. MSNAs are common among university students. They play a vital role in transforming people's life style and fostering social interaction. Throughout this study we tried to reveal impacts of MSNAs on college students' social life. The Facebook, Tweeter, WhatsApp and YouTube were chosen as the case because of their popularity among university students. The study found that MSNAs have positive influences in students' social live, including the ability to communicate with more people across greater distances and to raise social awareness on the current events. Compression of the means of the three dimensions with the theoretical means revealed significant differences in favour of each dimension. T-tests compressions for the gender and for education level revealed no significant differences in both variables whereas significant differences were found for the time spend variable. ANOVA for purposes of using (MSNAs) showed significant difference in favour of educational purposes, while ANOVA for type of applications used revealed no significant differences. The study concluded that the use of (MSNAs) at a moderate degree on students' social life and recommended the use of a large sample and scale of more variables of social life. Surveying a larger number of samples or expanding to universities across the country would be beneficial in creating a greater understanding of this research. This also could add a broader perspective for using (MSNAs) on students' social life from a more diverse population. The study also concluded that there is no negative impact of MSNAs on students' social life. If the students' social life has not been affected negatively this will lead to healthy social life and consequently might enhance and influence the learning process. Learning continually occurs through social interactions and influences from the community, media and the Internet. Through social interactions learning will 
occur and meaning will be constructed (Koch, 2013). Mobile social technology provides new and innovative methods to create social learning environments. It provides multiple windows for social interactions to create online communities of students who collaborate on specific issues (Sherman \& Kurshan, 2005). The study also recommended the encouragement of students to continue using MSNAs to exchange social issues among them and to form social groups to collaborate on specific issues.

\section{REFERENCES}

Abdelraheem, A. (2013, January). University students' use of social networking sites and its relation with some variables. Proceedings of the Eurasian Academic Conference, Antalya, Turkey, pp. 31-39.

Agbatogun, A. (2013). Interactive digital technologies' use in Southwest Nigerian universities. Educational Technology Research \& Development, 61(2), 333-357.

Ahn, J. (2011). The effect of social network sites on adolescents' academic and social development: Current theories and controversies. Journal of the American Society for Information Science \& Technology, 62(8), 1435-1445.

Alqahtani, M., \& Mohammad, H. (2015). Mobile Applications' impact on student performance and satisfaction. TOJET: The Turkish Online Journal of Educational Technology, 14(4), 102-112.

Al-Rahmi, W., \& Othman, M. (2013). The impact of social media use on academic performance among university students: A pilot study. Journal of Information Systems Research and Innovation, 4(3), pp. 1-10.

Alvarez, C., Alarcon, R., \& Nussbaum, M. (2011). Implementing collaborative learning activities in the classroom supported by one-to-one mobile computing: A design-based process. Journal of Systems and Software, 84(11), 1961-1976.

Banquil, K., \& Chua, N. A. (2009), Social Networking Sites affects one's academic performance adversely. Retrieved 29 March, 2017 from http://www.scribd.com/doc/28919575/SOCIALNETWORKING-SITESAFFECTONE\%E2\%80\%99S-ACADEMIC-PERFORMANCEADVERSELY.

Chatterjee, S. (2014). A sociological outlook of mobile phone use in society. International Journal of Interdisciplinary and Multidisciplinary Studies (IJIMS), l1(6), pp. 55-63.

Chiang, T. H., Yang, S. J., \& Hwang, G. J. (2014). An augmented reality-based mobile learning system to improve students' learning achievements and motivations in natural science inquiry activities. Educational Technology \& Society, 17(4), 352-365.

Eteokleous, N., Ktoridou, D., Stavrides, I., \& Michaelidis, M. (2012). Facebook-a social networking tool for educational purpose: Developing special interest groups.

Retrieved from http://www.icicte.org/Proceedings2012/Papers/09-2- Eteokleous.pdf 
Ferdig, R. E., Pytash, K. E., Kosko, K.W., Gandolfi, E., \& Mathews, R. (2016). Use and perceptions of mobile applications and technologies by those interested in special education. Kent, OH: Kent State University. Retrieved 05 March, 2017 from http://spedapps.kent.edu/2016survey.pdf.

Jesse, G. (2015). Smartphone and App Usage among College Students: Using Smartphones Effectively for Social and Educational Needs. Conference on Information Systems and Computing Education. Wilmington, North Carolina USA.

Kist, W. (2008). "I gave up myspace for lent": New teachers and social networking sites. Journal of Adolescent and Adult Literacy, 52, 245-286. doi: 10.1598/JAAL.52.3.7

Koch, C. (2013). Social cognition and social learning theories of education and technology. https://sites.google.com/a/boisestate.edu/edtechtheories/socialcognitionand-social-learning-theories-of-education-and-technology.

Mehmood, S., \& Taswir, T. (2013). The effects of social networking sites on the academic performance of students in college of applied sciences, nizwa, oman. International Journal of Arts and Commerce, 2(1), pp. 111-125.

Rajeev, M., \& Jobilal, (2015). Effects of social media on social relationships: A descriptive study on the impact of mobile phones among youth population. International Research Journal of Social Sciences, 4(2), 11-16.

Ruleman, A. (2012). Social media at the university: A demographic comparison. New Library World, 113(7), 316-332.

Sanchez-Gordon, S., \& Luján-Mora, S. (2016). How Could MOOCs become accessible? The case of edX and the future of inclusive online learning. Journal of Universal Computer Science, 22(1), 55-81.

Sherman, T. M., \& Kurshan, B. L. (2005). Constructing learning: Using technology to support teaching for understanding. Learning \& Leading with Technology, 32(5), 10-39.

Siddiqui, S., \& Singh, T. (2016). Social media its impact with positive and negative aspects. International Journal of Computer Applications Technology and Research, $5(2), 71-75$.

Siibak, A. (2009). Constructing the self through the photo selection- Visual impression management on social networking websites. Journal of Psychological Research on Cyberspace, 3(1) 1-6. Retrieved 13 May, 2017 from

http://www.cyberpsychology.eu/view.php?cisloclanku=2009061501\&article=1

Stollak, M. J., Vandenberg, A., Burklund, A., \& Weiss, S. (2011). Getting social: The impact of social networking usage on grades among college students. In Proceedings from ASBBS annual conference (pp. 859-865).

Tariq, W., Mehboob, M., Khan, M., \& Ullah, F. (2012). The impact of social media and social networks on education and students of Pakistan. International Journal of Computer Science Issues, 9, 407-411. 